\title{
Association of Working Hours with Biological Indices Related to the Cardiovascular System among Engineers in a Machinery Manufacturing Company
}

\author{
Takeshi SASAKI ${ }^{1 *}$, Kenji IWASAKI ${ }^{1}$, Tatsuo OKA ${ }^{1}$ and Naomi HISANAGA ${ }^{2}$ \\ ${ }^{1}$ Division of Work Stress Control, \\ ${ }^{2}$ Division of Hazard Assessment, National Institute of Industrial Health, 21-1, Nagao 6-chome, Tama-ku, Kawasaki \\ 214-8585, Japan
}

Received July 9, 1999 and accepted August 31, 1999

\begin{abstract}
A field survey of 278 engineers (20-59 years) in a machinery manufacturing company was conducted to investigate the association of working hours with biological indices related to the cardiovascular system (heart rate variability, blood pressure and serum levels of magnesium, dehydroepiandrosterone sulfate $<$ DHEA-S $>$ and cholesterol). Average working hours (defined as <"hours at workplace" + "half a commuting time">) and sleeping hours in this study were $60.2 \pm 6.3$ $\mathrm{hr} / \mathrm{week}$ and $6.6 \pm 0.8 \mathrm{hr} /$ day respectively. There were no significant relationships between working hours and biological indices related to the cardiovascular system, but sleeping hours was closely related to working hours negatively. Furthermore, the serum DHEA-S level was significantly related to sleeping hours positively. Combining these two results, it appeared that long working hours might lower the serum DHEA-S level due to the reduction of sleeping hours.
\end{abstract}

Key words: Working hours, Sleeping hours, Cardiovascular disease, Heart rate variability, Dehydroepiandrosterone sulfate, Fatigue

\section{Introduction}

In Japan there is the problem of health hazards with which work overload is associated. Long working hours is thought to be one of the main factors in work overload ${ }^{1-4}$. In order to establish health management guidelines on long working hours, we have been investigating the association of working hours with biological indices and confounding factors such as age and lifestyle.

In our previous papers ${ }^{5,6)}$ we reported field surveys of 71 male salesmen (in a machinery manufacturing company) and 147 male engineers (in an electronics manufacturing company) on the relationship between working hours and biological indices related to the cardiovascular system. In this paper we will report the third field survey with a purpose and method similar to those of the previous studies. We have made an effort to increase the number of subjects ( $n=278$ in this study). Furthermore, we partially changed the content of biological indices to be examined as follows: (1) the serum levels of dehydroepiandrosterone sulfate (DHEA-S) and magnesium (Mg) were measured for the first time, and (2) the data on total cholesterol (TC) and high-density lipoprotein cholesterol (HDL-C) were obtained for all of the subjects. It has been suggested that DHEA$\mathrm{S}$ and $\mathrm{Mg}$ are related to cardiovascular diseases ${ }^{7-9)}$. Our previous report ${ }^{5)}$ on salesmen suggested that long working hours might lower the TC level.

\footnotetext{
*To whom correspondence should be addressed.
} 


\section{Subjects and Methods}

\section{Subjects}

The subjects were 376 male engineers (20-59 years of age) in a machinery manufacturing company. They regularly worked 8 hours $(8: 30-17: 15$, lunch time $=45$ minutes $)$ a day, 5 days a week. Those who were under medical care and/or took medicines on the survey day $(n=59)$, and those who were lacking any data in the survey $(n=39)$ were excluded from the study. Finally, the number of the subjects for an analytical study was 278 and their age was $36.7 \pm 9.4$ years (mean \pm SD).

\section{Procedure for field study}

Surveys were made on 3 consecutive working days in June 1998. Each subject was examined on one of the survey days. The survey consisted of (1) a self-reported questionnaire (working hours, health conditions and lifestyle, and fatigue), (2) measurement of heart rate variability (HRV) at rest, and (3) data on systolic blood pressure (SBP), diastolic blood pressure (DBP), TC, HDL-C and body mass index (BMI) determined on the occasion of a regular health check conducted in June 1998. Blood samples for the determination of serum DHEA-S and $\mathrm{Mg}$ were obtained at the regular health check mentioned above with informed consent. The DHEA$\mathrm{S}$ (RIA method) and $\mathrm{Mg}$ (xylidyl blue method) levels were analyzed by SRL Inc. (Japan). A questionnaire on working hours, health conditions and lifestyle during the latest full month was filled out on each survey day or the day before the survey day. Investigation by questionnaire on fatigue and measurement of HRV was conducted on each survey day. A questionnaire on subjective fatigue defined by the Japan Association of Industrial Health ${ }^{10)}$ was filled out twice on the survey day in the morning (before leaving home) and in the afternoon (just before measurement of HRV). In this questionnaire, subjective fatigue at the time of writing the answers was asked about. HRV was measured in the afternoon (15:00-18:00) at the workplace. Before the measurement the subjects took a rest for $5 \mathrm{~min}$ or more. The R-R interval data were recorded by means of a heart rate monitor LRR-03 (GMS Co. Ltd., Japan) for $3 \mathrm{~min}$ in a sitting position with respiration controlled to once every $5 \sec (0.2 \mathrm{~Hz})$.

\section{Analysis of $H R V$}

Analysis of the frequency with MemCalc ${ }^{11)}$ (Suwa Trust Co., Japan) was conducted to obtain HF (power in the high frequency range, $0.15-0.30 \mathrm{~Hz}$ ) and LF (power in the low frequency range, $0.04-0.15 \mathrm{~Hz}$ ). The coefficient of variation of $\mathrm{HRV}$ in the high frequency range $\left(\mathrm{C}-\mathrm{CV}_{\mathrm{HF}}\right)^{12)}$ was calculated by the following equation: $\mathrm{C}-\mathrm{CV}_{\mathrm{HF}}=100 \times(\mathrm{HF})^{1 / 2}$ $R R$, where RR was the mean R-R interval. The LF/HF ratio was logarithmically converted to get normal distribution in statistical analysis.

\section{Weekly working hours}

The number of weekly working hours was defined by means of the following equation ${ }^{6}$ : Working hours (WH) $=$ "hours at workplace" + "half a commuting time", where "hours at workplace" is hours from arrival at to leaving the workplace. From the viewpoint of workload, we considered that the commuting load was equivalent to half the actual business load.

\section{Classification of working or sleeping hour subgroups}

The subjects were divided into 3 subgroups according to the 33rd and 66th percentile of working hours (57.1 and $63.3 \mathrm{hr} /$ week): short (SWH, <57.1 hr/week), medium (MWH, $57.1 \leqq,<63.3 \mathrm{hr} /$ week) and long (LWH, $63.3 \mathrm{hr} /$ week $\leqq$ ) working hour subgroups (Table 3 ). And the subjects were divided into 3 subgroups according to the 33rd and 66th percentile of sleeping hours ( 6 and $7 \mathrm{hr} /$ day): short (SSH, $<6 \mathrm{hr} /$ day), medium (MSH, $6 \leqq,<7 \mathrm{hr} /$ day) and long (LSH, $7 \mathrm{hr} /$ day $\leqq$ ) sleeping hour subgroups (Table 4 ).

\section{Statistics}

The correlations between biological indices and age or BMI were examined in Pearson's correlation coefficient. The relations between all parameters (biological indices, fatigue complaint rates, etc.) and working/sleeping hours were examined by two-way analysis of variance (ANOVA) with age and working/sleeping hours as factors. In the ANOVA, the subjects were categorized by two factors: working/sleeping hours (abovementioned short, medium and long hour ranges) and age (20-29, 30-39, 40-49 and 5059 year ranges). The difference in the mean values of the parameters for each working/sleeping hour subgroup was found by Fisher's least significance difference (LSD) method. Statistical significance was set at $p<0.05$.

This study was carried out by permission of the Ethics Committee of our institute.

\section{Results}

\section{Parameters on subjects in each age group}

Parameters on subjects in each age group are shown in 
Table 1. Parameters on subjects

\begin{tabular}{|c|c|c|c|c|c|}
\hline & \multicolumn{4}{|c|}{ Age group } & \multirow{2}{*}{ Overall } \\
\hline & $20-29$ & $30-39$ & $40-49$ & $50-59$ & \\
\hline Number & 78 & 108 & 53 & 39 & 278 \\
\hline Age (year) & $26.7 \pm 2.0$ & $34.1 \pm 2.9$ & $44.5 \pm 3.2$ & $53.4 \pm 2.7$ & $36.7 \pm 9.4$ \\
\hline Working hours (sum of $\mathrm{A}+\mathrm{B})(\mathrm{hr} /$ week) & $58.7 \pm 5.7$ & $61.1 \pm 6.8$ & $61.6 \pm 5.5$ & $58.6 \pm 6.4$ & $60.2 \pm 6.3$ \\
\hline (A) Hours at workplace*1 (hr/week) & $56.3 \pm 5.4$ & $57.7 \pm 6.7$ & $58.3 \pm 5.5$ & $55.4 \pm 5.8$ & $57.1 \pm 6.0$ \\
\hline (B) Half a commuting time (hr/week) & $2.4 \pm 1.8$ & $3.4 \pm 1.9$ & $3.3 \pm 1.4$ & $3.2 \pm 1.9$ & $3.1 \pm 1.8$ \\
\hline Sleeping hours (hr/day) & $6.6 \pm 0.7$ & $6.4 \pm 0.8$ & $6.7 \pm 0.7$ & $6.6 \pm 0.8$ & $6.6 \pm 0.8$ \\
\hline BMI $\left(\mathrm{kg} / \mathrm{m}^{2}\right)$ & $22.1 \pm 2.9$ & $22.7 \pm 3.0$ & $22.8 \pm 2.2$ & $23.0 \pm 2.2$ & $22.6 \pm 2.7$ \\
\hline $\mathrm{C}-\mathrm{CV}_{\mathrm{HF}}(\%)$ & $2.71 \pm 1.34$ & $2.17 \pm 0.95$ & $2.01 \pm 0.94$ & $1.59 \pm 0.93$ & $2.21 \pm 1.12$ \\
\hline $\log (\mathrm{LF} / \mathrm{HF})$ & $-0.16 \pm 0.36$ & $-0.01 \pm 0.38$ & $-0.12 \pm 0.39$ & $-0.07 \pm 0.52$ & $-0.08 \pm 0.40$ \\
\hline $\mathrm{SBP}(\mathrm{mmHg})$ & $124 \pm 11$ & $124 \pm 14$ & $125 \pm 14$ & $127 \pm 15$ & $124 \pm 14$ \\
\hline $\mathrm{DBP}(\mathrm{mmHg})$ & $71 \pm 7$ & $74 \pm 9$ & $79 \pm 10$ & $81 \pm 8$ & $75 \pm 9$ \\
\hline $\mathrm{Mg}(\mathrm{mg} / \mathrm{dl})$ & $2.1 \pm 0.1$ & $2.2 \pm 0.1$ & $2.2 \pm 0.1$ & $2.2 \pm 0.1$ & $2.2 \pm 0.1$ \\
\hline DHEA-S $(\mu \mathrm{g} / \mathrm{ml})$ & $3.09 \pm 0.95$ & $2.94 \pm 0.97$ & $2.48 \pm 0.89$ & $2.04 \pm 0.95$ & $2.77 \pm 1.01$ \\
\hline $\mathrm{TC}(\mathrm{mg} / \mathrm{dl})$ & $184 \pm 29$ & $204 \pm 33$ & $218 \pm 38$ & $213 \pm 33$ & $202 \pm 35$ \\
\hline HDL-C (mg/dl) & $60 \pm 12$ & $59 \pm 14$ & $62 \pm 15$ & $63 \pm 15$ & $60 \pm 14$ \\
\hline \multicolumn{6}{|c|}{ Fatigue complaint rate $I^{* 2}$ (Drowsiness and dullness) } \\
\hline Morning (\%) & $30.9 \pm 19.7$ & $28.2 \pm 23.9$ & $25.3 \pm 25.9$ & $19.0 \pm 21.0$ & $27.1 \pm 23.0$ \\
\hline Afternoon $(\%)$ & $16.5 \pm 19.2$ & $16.9 \pm 20.6$ & $14.9 \pm 18.0$ & $13.8 \pm 18.0$ & $16.0 \pm 19.3$ \\
\hline \multicolumn{6}{|c|}{ Fatigue complaint rate II (Difficulty in concentrating attention) } \\
\hline Morning (\%) & $18.5 \pm 22.6$ & $16.5 \pm 22.6$ & $21.7 \pm 27.6$ & $19.5 \pm 23.8$ & $18.5 \pm 23.7$ \\
\hline Afternoon (\%) & $12.8 \pm 21.5$ & $11.9 \pm 21.9$ & $17.4 \pm 22.9$ & $17.2 \pm 27.2$ & $13.9 \pm 22.8$ \\
\hline \multicolumn{6}{|c|}{ Fatigue complaint rate III (Feeling of local physical abnormality) } \\
\hline Morning (\%) & $10.1 \pm 11.8$ & $9.1 \pm 12.3$ & $10.4 \pm 13.9$ & $11.0 \pm 13.1$ & $9.9 \pm 12.5$ \\
\hline Afternoon (\%) & $6.5 \pm 8.9$ & $9.2 \pm 13.2$ & $8.5 \pm 12.5$ & $7.9 \pm 13.0$ & $8.1 \pm 12.0$ \\
\hline
\end{tabular}

Values are the mean \pm SD except the number. ${ }^{* 1}$ : Defined as hours from arrival at to leaving the workplace. ${ }^{* 2}$ : Fatigue complaint rate is (number of "yes" answer/number of questions) $\times 100(\%)$.

Table 1. Working hours was $60.2 \mathrm{hr} /$ week in the overall group, and longest in the 40-49 year group (61.6 hr/week). Sleeping hours was $6.6 \mathrm{hr} /$ day in the overall group, and shortest in the 30-39 year group ( $6.4 \mathrm{hr} /$ day). Fatigue complaint rates in the overall group were fatigue I $>$ fatigue II $>$ fatigue III both in the morning and afternoon. Fatigue complaint rates in the morning were higher than those in the afternoon, both in each fatigue category and in each age or the overall group.

Several biological indices related to the cardiovascular system increased or decreased with age. Significant correlations between biological indices and age were found (shown in Table 2). Those were positive for DBP, $\mathrm{Mg}$ and $\mathrm{TC}$, and negative in $\mathrm{C}-\mathrm{CV}_{\mathrm{HF}}$ and DHEA-S. Correlations between biological indices and BMI are also shown in Table 2. $\mathrm{C}-\mathrm{CV}_{\mathrm{HF}}$, the LF/HF ratio, SBP, DBP, TC and HDL-C had significant correlations with BMI.

\section{Relation between working hours and other parameters on subjects}

The relation between working hours and other parameters
Table 2. Correlations of biological indices with age or BMI in all subjects $(\mathbf{n}=\mathbf{2 7 8})$

\begin{tabular}{lcc}
\hline & Age & BMI \\
\hline BMI & $0.119^{*}$ & - \\
${\mathrm{C}-C V_{\mathrm{HF}}}_{\log (\mathrm{LF} / \mathrm{HF})}$ & $0.335^{* * *}$ & $-0.191^{* *}$ \\
SBP & 0.054 & $0.169^{* *}$ \\
$\mathrm{DBP}$ & 0.066 & $0.373^{* * *}$ \\
Mg & $0.355^{* * *}$ & $0.272^{* * *}$ \\
DHEA-S & $0.228 * * *$ & -0.049 \\
TC & $-0.357 * * *$ & 0.092 \\
HDL-C & $0.340^{* * *}$ & $0.249 * * *$ \\
\hline
\end{tabular}

Values are the Pearson's correlation coefficient. *: $\mathrm{p}<0.05$, $* *$ : $\mathrm{p}<0.01, * * *$ : $\mathrm{p}<0.001$.

shown in Table 3 was significant only in sleeping hours $(\mathrm{p}<0.001)$. On the comparison of sleeping hours among three working hour subgroups, sleeping hours for LWH was significantly shorter than those for SWH and MWH. Although no significant effects of working hours on 
Table 3. Relations between all parameters and working hours (WH)

\begin{tabular}{|c|c|c|c|c|c|c|c|c|c|}
\hline \multirow[t]{2}{*}{ Parameter } & \multicolumn{3}{|c|}{ F-value by two-way ANOVA } & \multicolumn{3}{|c|}{$\begin{array}{c}\text { Mean } \pm \text { SD of parameters among } \\
\text { working hour subgroups }\end{array}$} & \multicolumn{3}{|c|}{$\begin{array}{l}\text { Multiple comparison by } \\
\text { Fisher's LSD }\end{array}$} \\
\hline & Age & WH & Age*WH*1 $^{*}$ & SWH $(n=92)$ & MWH (n=90) & LWH ( $n=96)$ & S-M*2 & $\mathrm{M}-\mathrm{L}^{* 3}$ & L-S*4 \\
\hline Age (year) & $1018.39 * * *$ & 0.01 & 1.67 & $36.4 \pm 10.6$ & $36.9 \pm 9.2$ & $36.8 \pm 8.5$ & & & \\
\hline Working hours (hr/week) & $3.63^{*}$ & $721.40 * * *$ & 1.20 & $53.1 \pm 2.8$ & $60.0 \pm 1.7$ & $67.1 \pm 2.8$ & $* * *$ & $* * *$ & $* * *$ \\
\hline Sleeping hours (hr/day) & 2.09 & $13.85 * * *$ & 0.84 & $6.7 \pm 0.8$ & $6.7 \pm 0.7$ & $6.2 \pm 0.7$ & & $* * *$ & $* * *$ \\
\hline BMI $\left(\mathrm{kg} / \mathrm{m}^{2}\right)$ & 1.34 & 0.55 & 0.32 & $22.8 \pm 3.5$ & $22.5 \pm 2.0$ & $22.5 \pm 2.5$ & & & \\
\hline $\mathrm{C}-\mathrm{CV}_{\mathrm{HF}}(\%)$ & $10.48 * * *$ & 0.11 & 0.52 & $2.20 \pm 0.98$ & $2.25 \pm 1.27$ & $2.19 \pm 1.12$ & & & \\
\hline $\log (\mathrm{LF} / \mathrm{HF})$ & $2.17^{\#}$ & 0.15 & 1.00 & $-0.10 \pm 0.40$ & $-0.09 \pm 0.40$ & $-0.06 \pm 0.42$ & & & \\
\hline SBP (mmHg) & 0.67 & 0.43 & 1.19 & $125 \pm 12$ & $124 \pm 15$ & $123 \pm 14$ & & & \\
\hline DBP (mmHg) & $14.69 * * *$ & 0.11 & 1.35 & $75 \pm 8$ & $75 \pm 10$ & $75 \pm 10$ & & & \\
\hline $\mathrm{Mg}(\mathrm{mg} / \mathrm{dl})$ & $5.94 * * *$ & 0.53 & 1.62 & $2.2 \pm 0.1$ & $2.2 \pm 0.1$ & $2.2 \pm 0.1$ & & & \\
\hline DHEA-S $(\mu \mathrm{g} / \mathrm{ml})$ & $13.70^{* * *}$ & 0.92 & 1.27 & $2.80 \pm 1.03$ & $2.84 \pm 1.07$ & $2.67 \pm 0.94$ & & & \\
\hline $\mathrm{TC}(\mathrm{mg} / \mathrm{dl})$ & $14.33 * * *$ & 1.68 & $2.84 *$ & $204 \pm 36$ & $204 \pm 36$ & $199 \pm 33$ & & & \\
\hline HDL-C (mg/dl) & 1.00 & 0.34 & 0.29 & $60 \pm 14$ & $62 \pm 15$ & $60 \pm 12$ & & & \\
\hline \multicolumn{10}{|c|}{ Fatigue complaint rate $I^{* 5}$ (Drowsiness and dullness) } \\
\hline Morning (\%) & $2.53^{\#}$ & 2.14 & 0.38 & $23.6 \pm 19.9$ & $27.1 \pm 22.9$ & $30.5 \pm 25.6$ & & & \\
\hline Afternoon $(\%)$ & 0.29 & 1.71 & 0.49 & $14.3 \pm 18.6$ & $14.4 \pm 17.3$ & $19.0 \pm 21.5$ & & & \\
\hline \multicolumn{10}{|c|}{ Fatigue complaint rate II (Difficulty in concentrating attention) } \\
\hline Morning (\%) & 0.64 & 1.66 & 0.80 & $17.4 \pm 21.7$ & $15.9 \pm 22.5$ & $21.9 \pm 26.5$ & & & \\
\hline Afternoon $(\%)$ & 1.03 & 1.05 & 1.02 & $12.0 \pm 19.8$ & $13.1 \pm 25.6$ & $16.6 \pm 22.7$ & & & \\
\hline \multicolumn{10}{|c|}{ Fatigue complaint rate III (Feeling of local physical abnormality) } \\
\hline Morning (\%) & 0.36 & 1.05 & 0.65 & $8.5 \pm 10.6$ & $10.2 \pm 12.0$ & $10.9 \pm 14.6$ & & & \\
\hline Afternoon (\%) & 0.64 & 0.58 & 0.88 & $7.2 \pm 12.6$ & $7.9 \pm 9.9$ & $9.3 \pm 13.1$ & & & \\
\hline
\end{tabular}

SWH: short working hour subgroup, MWH: medium working hour subgroup, LWH: long working hour subgroup. ${ }^{* 1}$ : Interaction between age and WH. *2: Between SWH and MWH. *3: Between MWH and LWH. *4: Between LWH and SWH. *5: Fatigue complaint rate is (number of "yes" answer/number of questions) $\times 100(\%)$. \#: $\mathrm{p}<0.1, *: \mathrm{p}<0.05, * * *: \mathrm{p}<0.001$.

biological indices were found, significant interaction between age and working hours was found in TC. As shown in Table 5 , the TC level for SWH was higher than those for MWH and LWH in the 40-49 year group, and the TC level for MWH was higher than those for SWH and LWH in the 3039 year group.

\section{Relation between sleeping hours and other parameters on subjects}

The relation between sleeping hours and other parameters shown in Table 4 was significant in serum DHEA-S $(p<0.05)$ and four kinds of fatigue complaint rate $(\mathrm{p}<0.001$ or $\mathrm{p}<0.05)$. The serum DHEA-S level for SSH was significantly lower than those for MSH and LSH. Results of the comparison for fatigue complaint rates among the three sleeping hour subgroups were different from those for DHEA-S. Fatigue complaint rates for SSH and MSH were significantly higher than those for LSH in fatigue I in the morning. Furthermore, three other kinds of fatigue complaint rates for MSH were significantly higher than those for LSH. There was a tendency $(p<0.1)$ in the relation between sleeping hours and TC. On the comparison of TC among the three sleeping hour subgroups, TC decreased on average with the decrease in sleeping hours. Significant interactions between age and sleeping hours were found in the LF/HF ratio and DBP. Although the $\mathrm{LF} / \mathrm{HF}$ ratio for $\mathrm{SSH}$ was lower than those for MSH and LSH in the 30-39 year group, the LF/HF ratio for SSH was higher than those for MSH and LSH in the 50-59 year group (Table 5). As for DBP, significant differences were found between some sleeping hour subgroups in the 20-29 and 40-49 year groups (Table 5).

\section{Discussion}

Working hours of the engineers in this workplace (60.2 $\mathrm{hr} /$ week) was $2.9 \mathrm{hr} /$ week shorter than that of the engineers in the previous survey) $(63.1 \mathrm{hr} /$ week $)$. And sleeping hours in this survey $(6.6 \mathrm{hr} / \mathrm{day})$ was $0.4 \mathrm{hr} /$ day longer than that in the previous survey ${ }^{6}$ ( $6.2 \mathrm{hr} /$ day). Therefore, the working conditions at the company in this study are thought to be 
Table 4. Relations between all parameters and sleeping hours (SH)

\begin{tabular}{|c|c|c|c|c|c|c|c|c|c|}
\hline \multirow[t]{2}{*}{ Parameter } & \multicolumn{3}{|c|}{ F-value by two-way ANOVA } & \multicolumn{3}{|c|}{$\begin{array}{c}\text { Mean } \pm \text { SD of parameters among } \\
\text { sleeping hour subgroups }\end{array}$} & \multicolumn{3}{|c|}{$\begin{array}{l}\text { Multiple comparison by } \\
\text { Fisher's LSD }\end{array}$} \\
\hline & Age & SH & Age*SH*1 & $\mathrm{SSH}(\mathrm{n}=23)$ & MSH $(n=138)$ & LSH $(n=117)$ & $\mathrm{S}-\mathrm{M}^{* 2}$ & $\mathrm{M}-\mathrm{L}^{* 3}$ & $\mathrm{~L}-\mathrm{S}^{* 4}$ \\
\hline Age (year) & $1048.46 * * *$ & $2.93^{\#}$ & $2.16^{*}$ & $36.4 \pm 9.5$ & $36.2 \pm 9.3$ & $37.4 \pm 9.7$ & & & \\
\hline Working hours (hr/week) & $4.46^{* *}$ & $11.39 * * *$ & $1.90^{\#}$ & $62.4 \pm 7.1$ & $61.5 \pm 6.5$ & $58.2 \pm 5.4$ & & $* * *$ & $* *$ \\
\hline Sleeping hours (hr/day) & 0.22 & $516.77^{* * *}$ & 0.51 & $5.2 \pm 0.3$ & $6.2 \pm 0.2$ & $7.3 \pm 0.4$ & $* * *$ & $* * *$ & $* * *$ \\
\hline $\mathrm{BMI}\left(\mathrm{kg} / \mathrm{m}^{2}\right)$ & 1.24 & 0.56 & 0.47 & $23.0 \pm 3.5$ & $22.7 \pm 2.7$ & $22.4 \pm 2.6$ & & & \\
\hline $\mathrm{C}-\mathrm{CV}_{\mathrm{HF}}(\%)$ & $10.81^{* * *}$ & 0.43 & 1.74 & $2.27 \pm 1.25$ & $2.16 \pm 0.99$ & $2.26 \pm 1.25$ & & & \\
\hline $\log (\mathrm{LF} / \mathrm{HF})$ & $2.35^{\#}$ & 0.10 & $4.06^{* * *}$ & $-0.08 \pm 0.51$ & $-0.07 \pm 0.40$ & $-0.10 \pm 0.39$ & & & \\
\hline $\mathrm{SBP}(\mathrm{mmHg})$ & 0.70 & 0.23 & 1.61 & $125 \pm 17$ & $124 \pm 13$ & $125 \pm 14$ & & & \\
\hline DBP (mmHg) & $15.05^{* * *}$ & 0.06 & $2.88 * *$ & $75 \pm 11$ & $75 \pm 9$ & $75 \pm 10$ & & & \\
\hline $\mathrm{Mg}(\mathrm{mg} / \mathrm{dl})$ & $5.70^{* * *}$ & 0.30 & 1.26 & $2.2 \pm 0.2$ & $2.2 \pm 0.1$ & $2.2 \pm 0.1$ & & & \\
\hline DHEA-S $(\mu \mathrm{g} / \mathrm{ml})$ & $14.15^{* * *}$ & $3.33 *$ & 1.64 & $2.34 \pm 1.04$ & $2.86 \pm 1.04$ & $2.75 \pm 0.95$ & $*$ & & $*$ \\
\hline $\mathrm{TC}(\mathrm{mg} / \mathrm{dl})$ & $13.08 * * *$ & $2.47^{\#}$ & 0.56 & $190 \pm 29$ & $201 \pm 35$ & $207 \pm 35$ & & & \\
\hline HDL-C (mg/dl) & 1.04 & 0.99 & 1.67 & $62 \pm 13$ & $59 \pm 13$ & $62 \pm 14$ & & & \\
\hline \multicolumn{10}{|c|}{ Fatigue complaint rate $I^{* 5}$ (Drowsiness and dullness) } \\
\hline Morning (\%) & $2.60^{\#}$ & $7.83^{* * *}$ & 0.49 & $30.9 \pm 19.3$ & $31.8 \pm 25.6$ & $20.9 \pm 18.9$ & & $* * *$ & $*$ \\
\hline Afternoon (\%) & 0.25 & $3.14^{*}$ & 0.16 & $15.7 \pm 13.4$ & $18.8 \pm 22.2$ & $12.6 \pm 15.8$ & & $*$ & \\
\hline \multicolumn{10}{|c|}{ Fatigue complaint rate II (Difficulty in concentrating attention) } \\
\hline Morning (\%) & 0.76 & $3.04 *$ & 0.84 & $17.8 \pm 18.1$ & $21.7 \pm 26.4$ & $14.7 \pm 20.9$ & & $*$ & \\
\hline Afternoon (\%) & 1.06 & $2.68^{\#}$ & 0.44 & $9.1 \pm 17.6$ & $17.0 \pm 26.2$ & $11.2 \pm 18.6$ & & & \\
\hline \multicolumn{10}{|c|}{ Fatigue complaint rate III (Feeling of local physical abnormality) } \\
\hline Morning (\%) & 0.32 & $2.57^{\#}$ & 0.43 & $8.3 \pm 8.9$ & $11.6 \pm 13.8$ & $8.2 \pm 11.3$ & & & \\
\hline Afternoon (\%) & 0.78 & $3.27 *$ & 0.52 & $5.2 \pm 5.9$ & $9.9 \pm 13.7$ & $6.6 \pm 10.2$ & & $*$ & \\
\hline
\end{tabular}

SSH: short sleeping hour subgroup, MSH: medium sleeping hour subgroup, LSH: long sleeping hour subgroup. *1: Interaction between age and SH. *2: Between SSH and MSH. *3: Between MSH and LSH. *4: Between LSH and SSH. *5: Fatigue complaint rate is (number of "yes" answer/number of questions) $\times 100(\%) . \#:$ p $<0.1, *: \mathrm{p}<0.05, * *$ : $\mathrm{p}<0.01, * * *$ : $\mathrm{p}<0.001$.

slightly better than those at the company in the previous study ${ }^{6}$.

In this study no significant relationships were found between working hours and biological indices related to the cardiovascular system, but sleeping hours was closely related to working hours negatively. Furthermore, the serum DHEA$S$ level was significantly related to sleeping hours positively. Combining these two results, it appeared that long working hours might lower the serum DHEA-S level due to the reduction in sleeping hours. This idea is supported partly by the fact that the serum DHEA-S level for LWH was lower than those for SWH and MWH on average (Table 3). It is well-known that the serum DHEA-S level decreases with age $^{13,14)}$. Recently the relation between the serum DHEA-S level and health has been extensively studied. Epidemiological studies ${ }^{7,8)}$ have suggested that a low level of serum DHEA-S is related to cardiovascular diseases. Other studies reported that: (1) DHEA administration activated immune function in age-advanced men ${ }^{15)}$, (2) DHEA administration also changed the electrophysiological indices of the central nervous system in elderly men ${ }^{16)}$, and (3) the serum DHEA-S level was lowered by perceived stress ${ }^{17}$. The serum DHEA-S level has therefore been becoming a valuable health index. To our knowledge, the association of working/sleeping hours with DHEA-S has not yet been reported at all. Further study will have to be done to confirm our present results.

In addition to DHEA-S, TC was related to sleeping (working) hours to some extent in this study. Although the relation between fatigue complaint rates and working hours was not significant, fatigue complaint rates for LWH were highest among the three working hour subgroups. TC and fatigue complaint rates are also thought to be important as measures of the effect of long working hours. The serum $\mathrm{Mg}$ level was not related to working/sleeping hours in this study.

In this study, significant interactions were found in TC between working hours and age, and in the LF/HF ratio and DBP between sleeping hours and age. These results mean that the association of working/sleeping hours with some 
Table 5. Some biological indices in each working/sleeping hours $\times$ age subgroup

\begin{tabular}{|c|c|c|c|c|c|c|c|c|c|c|c|c|}
\hline & \multicolumn{6}{|c|}{ 20-29 years } & \multicolumn{6}{|c|}{ 30-39 years } \\
\hline & \multirow{2}{*}{ Short*1 } & \multirow{2}{*}{ Medium*2 } & \multirow{2}{*}{ Long*3 } & \multirow{2}{*}{\multicolumn{3}{|c|}{$\frac{\text { Fisher's LSD }}{\text { S-M }^{* 4} \mathrm{M}-\mathrm{L}^{* 5} \mathrm{~L}-\mathrm{S}^{* 6}}$}} & \multirow{2}{*}{ Short } & \multirow{2}{*}{ Medium } & \multirow{2}{*}{ Long } & \multicolumn{3}{|c|}{ Fisher's LSD } \\
\hline & & & & & & & & & & S-M & M-L & L-S \\
\hline \multicolumn{13}{|c|}{ Classification by working hours } \\
\hline Number & 31 & 24 & 23 & & & & 33 & 34 & 41 & & & \\
\hline $\mathrm{TC}(\mathrm{mg} / \mathrm{dl})$ & $187 \pm 32$ & $185 \pm 29$ & $180 \pm 25$ & & & & $199 \pm 29$ & $216 \pm 36$ & $197 \pm 31$ & $*$ & * & \\
\hline \multicolumn{13}{|c|}{ Classification by sleeping hours } \\
\hline Number & 5 & 39 & 34 & & & & 13 & 55 & 40 & & & \\
\hline DHEA-S $(\mu \mathrm{g} / \mathrm{ml})$ & $3.25 \pm 0.93$ & $3.22 \pm 0.99$ & $2.92 \pm 0.91$ & & & & $2.20 \pm 0.90$ & $3.11 \pm 0.93$ & $2.96 \pm 0.95$ & $* *$ & & $*$ \\
\hline $\log (\mathrm{LF} / \mathrm{HF})$ & $-0.26 \pm 0.60$ & $-0.16 \pm 0.33$ & $-0.14 \pm 0.37$ & & & & $-0.24 \pm 0.29$ & $0.00 \pm 0.41$ & $0.05 \pm 0.36$ & $*$ & & $*$ \\
\hline \multirow[t]{4}{*}{$\mathrm{DBP}(\mathrm{mmHg})$} & $65 \pm 6$ & $73 \pm 8$ & $70 \pm 6$ & $*$ & $\#$ & & $75 \pm 9$ & $74 \pm 9$ & $74 \pm 10$ & & & \\
\hline & \multicolumn{6}{|c|}{$40-49$ years } & \multicolumn{6}{|c|}{$50-59$ years } \\
\hline & \multirow{2}{*}{ Short } & \multirow{2}{*}{ Medium } & \multirow{2}{*}{ Long } & \multicolumn{3}{|c|}{ Fisher's LSD } & \multirow{2}{*}{ Short } & \multirow{2}{*}{ Medium } & \multirow{2}{*}{ Long } & \multicolumn{3}{|c|}{ Fisher's LSD } \\
\hline & & & & S-M & M-L & L-S & & & & S-M & M-L & L-S \\
\hline \multicolumn{13}{|c|}{ Classification by working hours } \\
\hline Number & 11 & 21 & 21 & & & & 17 & 11 & 11 & & & \\
\hline $\mathrm{TC}(\mathrm{mg} / \mathrm{dl})$ & $248 \pm 31$ & $207 \pm 40$ & $214 \pm 34$ & $* * *$ & & $* *$ & $217 \pm 33$ & $207 \pm 32$ & $214 \pm 35$ & & & \\
\hline \multicolumn{13}{|c|}{ Classification by sleeping hours } \\
\hline Number & 1 & 25 & 27 & & & & 4 & 19 & 16 & & & \\
\hline DHEA-S $(\mu \mathrm{g} / \mathrm{ml})$ & 1.67 & $2.27 \pm 0.86$ & $2.71 \pm 0.89$ & & $\#$ & & $1.86 \pm 1.28$ & $2.18 \pm 1.07$ & $1.91 \pm 0.74$ & & & \\
\hline $\log (\mathrm{LF} / \mathrm{HF})$ & 0.02 & $-0.06 \pm 0.40$ & $-0.19 \pm 0.38$ & & & & $0.66 \pm 0.37$ & $-0.09 \pm 0.50$ & $-0.23 \pm 0.42$ & $* * *$ & & $* * *$ \\
\hline DBP (mmHg) & 86 & $75 \pm 9$ & $82 \pm 9$ & & $* *$ & & $83 \pm 13$ & $80 \pm 7$ & $82 \pm 8$ & & & \\
\hline
\end{tabular}

Some biological indices on which effect of sleeping hours or significant interactions between age and working/sleeping hours were significant. Values of biological indices are the mean \pm SD. ${ }^{*}$ : : Short working hour subgroup (SWH) or short sleeping hour subgroup (SSH). ${ }^{* 2}$ : Medium working hour subgroup (MWH) or medium sleeping hour subgroup (MSH). ${ }^{* 3}$ : Long working hour subgroup (LWH) or long sleeping hour subgroup (LSH). *4: Between SWH (SSH) and MWH (MSH). *5: Between MWH (MSH) and LWH (LSH). *6: Between LWH (LSH) and SWH (SSH). *: p<0.1, *: p<0.05, **: p<0.01, ***: p<0.001.

biological indices depend on age. In our previous papers ${ }^{5}$, ${ }^{6}$ ) we reported the significant relationships of working hours with TC, SBP and urinary noradrenaline in specific age groups. These age-dependent results are thought to be very important in the effect of working/sleeping hours on health, but the number of subjects in each subgroup defined by age and working/sleeping hours was rather small. To confirm the results on the interaction obtained in this study, it is necessary to conduct another survey on a larger population.

\section{Acknowledgement}

This work was partly supported by "Cooperative System for Supporting Priority Research" of Japan Science and Technology Corporation.

\section{References}

1) Tokunaga $Y$ (1994) Overwork and health injuries. The Keizai Bunseki (The Economic Analysis). 133, 1-94 (in Japanese).

2) Uehata $T$ (1993) Study of karoshi. Japan Planning Center, Tokyo (in Japanese).

3) Kageyama T, Nishikido N, Kobayashi T, Kurokawa $Y$, Kaneko T, Kabuto M (1998) Long commuting time, extensive overtime, and sympathodominant state assessed in terms of short-term heart rate variability among male white-collar workers in the Tokyo Megalopolis. Ind Health 36, 209-17.

4) Sokejima $S$, Kagamimori $S$ (1998) Working hours as a risk factor for acute myocardial infarction in Japan: case-control study. BMJ 317, 775-80.

5) Iwasaki K, Sasaki T, Oka T, Hisanaga N (1998) Effect of working hours on biological functions related to 
cardiovascular system among salesmen in a machinery manufacturing company. Ind Health 36, 361-7.

6) Sasaki T, Iwasaki K, Oka T, Hisanaga N, Ueda T, Takada Y, Fujiki Y (1999) Effect of working hours on cardiovascular-autonomic nervous functions among engineers in an electronics manufacturing company. Ind Health 37, 55-61.

7) Barrett-Connor E, Khaw KT, Yen SSC (1986) A prospective study of dehydroepiandrosterone sulfate, mortality, and cardiovascular disease. N Engl J Med 315, 1519-24.

8) Barrett-Connor E, Goodman GD (1995) The epidemiology of DHEAS and cardiovascular disease. Ann NY Acad Sci 774, 259-70.

9) Itokawa Y, Saito N (1995) Magnesium. Koseikan, Tokyo (in Japanese).

10) Yoshitake H (1971) Methodological study on the inquiry into subjective symptoms of fatigue. J Sci Labour 47, 797-802.

11) Tanaka $Y$ (1996) User's manual of MemCalc system. Suwa Trust Co., Sapporo (in Japanese).

12) Hayano J (1996) Assessment of autonomic nervous function by heart rate variability. In: Cardiovascular diseases and autonomic nervous function. ed. by Inoue H, 58-88, Igakushoin, Tokyo (in Japanese).

13) Yamaji T, Ibayashi H (1969) Plasma dehydroepiandrosterone sulfate in normal and pathological conditions. J Clin Endocrinol Metab 29, 273-8.

14) Orentreich N, Brind JL, Rizer RL, Vogelman JH (1984) Age changes and sex differences in serum dehydroepiandrosterone sulfate concentrations throughout adulthood. J Clin Endocrinol Metab 59, 5515.

15) Khorram O, Vu L, Yen SSC (1997) Activation of immune function by dehydroepiandrosterone (DHEA) in age-advanced men. J Gerontol Med Sci 52, M1-7.

16) Wolf OT, Naumann E, Hellhammer DH, Kirschbaum C (1998) Effects of dehydroepiandrosterone replacement in elderly men on event-related potentials, memory, and well-being. J Gerontol Med Sci 53, M38590.

17) Labbate LA, Fava M, Oleshansky M, Zoltec J, Littman A, Harig P (1995) Physical fitness and perceived stress. Relationships with coronary artery disease risk factors. Psychosomatics 36, 555-60. 